\title{
DESULTORY REMARKS ON THE LEGISLATIVE IMPROVEMENT OF THE RUSSIAN FEDERATION IN THE FIELD OF CROSS-BORDER MARRIAGE AND FAMILY RELATIONS
}

\author{
Igor B. Ilovaisky \\ Volgograd State University, Volgograd, Russian Federation \\ Valeria Yu. Dolgova \\ Limited Liability Company “CrimExpertYug”, Volgograd, Russian Federation
}

\begin{abstract}
Introduction: Russian society is regularly shaken by the reports of the Russian families who have left for permanent residence abroad. It is shocking that abroad, as it turns out, for one reason or another, often far-fetched, it is possible to withdraw children from the family and commit them to more trustworthy, if it seems so to the competent authorities, adoptive parents, to accuse a mother of kidnapping her own child, if she took the child to Russia, to refuse the recognition of the validity of marriages if they were concluded in the territory of this country, etc. All these cases show that the legal regulators that exist in that regard in Russia do not clearly work in other states and do not create sufficient guarantees of respect for the rights of Russian nationals. In this regard, the purpose of the paper is to consider the current state and prospects of normative improvement of the domestic norms of private international law in the regulation of cross-border family and marriage relations. Methods: the research is based on the use of logical, dialectical techniques and methods of scientific knowledge, comparative legal and legal-technical analysis of wording of normative acts and materials of the law enforcement practice. The study was the analysis of Russia's participation in the standardized agreements both of conflict and substantive nature in the field of international marriage and family relations and the status of the national law in this area. The results of the review became the basis for the conclusion that the Russian legislator was not sufficiently attentive to the processes of international unification and harmonization of the norms governing marriage and family relations with a foreign element. In this regard, the proposals were made to improve the current domestic family law and the acts of law enforcement practice.

Key words: private international law, international family and marriage relations, unification and harmonization of cross-border family and marriage relations, conflict and substantive law, concubinage, same-sex marriage.
\end{abstract}

Citation. Ilovaisky I.B., Dolgova V.Yu. Desultory Remarks on the Legislative Improvement of the Russian Federation in the Field of Cross-Border Marriage and Family Relations. Legal Concept, 2019, vol. 18, no. 4, pp. 111118. (in Russian). DOI: https://doi.org/10.15688/lc.jvolsu.2019.4.15 БРАЧНО-СЕМЕЙНЫХ ОТНОШЕНИЙ

\author{
Игорь Борисович Иловайский \\ Волгоградский государственный университет, г. Волгоград, Российская Федерация \\ Валерия Юрьевна Долгова \\ ООО «КримЭкспертЮг», г. Волгоград, Российская Федерация
}


Введение: российское общество регулярно потрясают сообщения о российских семьях, выехавших на постоянное жительство за рубеж. Шокирует то, что за границей, оказывается, по тем или иным причинам, часто надуманным, можно изъять детей из семьи и передать на воспитание более благонадежным, если так кажется компетентным органам, приемным родителям. Обвинить в краже собственного ребенка его мать, если она вывезла ребенка в Россию; отказать в признании действительности брака, если он был заключен на территории нашей страны, и т. п. - все эти случаи свидетельствуют о том, что правовые регуляторы, существующие по этому поводу в России, явно не работают в других государствах и не создают достаточных гарантий соблюдения прав граждан РФ. В связи с этим целью настоящей публикации является рассмотрение современного состояния и перспектив нормативного совершенствования отечественных норм международного частного права в части регулирования трансграничных семейно-брачных отношений. Методы: изыскание основано на применении логического, диалектического приемов и способов научного познания, сравнительно-правового и юридико-технического анализа текстов нормативных актов и материалов правоприменительной практики. В результате исследования был проведен анализ участия Российской Федерации в унифицированных соглашениях как коллизионного, так и материально-правового характера в области международных брачно-семейных отношений, а также состояния национальных норм права в этой сфере. Итоги рассмотрения стали основой для вывода, что российский законодатель недостаточно внимательно относится к процессам международной унификации и гармонизации норм, регламентирующих брачно-семейные отношения с иностранным элементом. Внесены предложения по совершенствованию действующего отечественного семейного права и актов правоприменительной практики.

Ключевые слова: международное частное право, международные семейно-брачные отношения, унификация и гармонизация трансграничных семейно-брачных отношений, коллизионные и материально-правовые нормы, конкубинат, однополый брак.

Цитирование. Иловайский И. Б., Долгова В. Ю. Отдельные замечания по совершенствованию законодательства РФ в сфере трансграничных брачно-семейных отношений // Legal Concept = Правовая парадигма. 2019. - T. 18, № 4. - C. 111-118. - DOI: https://doi.org/10.15688/lc.jvolsu.2019.4.15

\section{Введение}

Из всей совокупности общественных отношений семейно-брачные отношения представляют собой один из наиболее сложных комплексов социальных взаимосвязей, которые складываются на основе родства и психологических привязанностей, совместных духовных ценностей и общей собственности. Институт брака прошел многовековой путь развития, тем не менее не редки случаи, когда указанные правоотношения становятся конгломератом различных переплетений и тонкостей, и часто их исполнение осуществляется без конфликтов и бурных эмоций. А если добавить к таким отношениям элементы международности и связи с правом нескольких государств, то разрешение возникших в этой области споров может превратиться в весьма загадочный ребус... В таких ситуациях только право может помочь цивилизованно разрешить создавшиеся проблемы, но семейные отношения в каждой конкретной стране формируются исторически под влиянием религии, традиций, бы- товых и этических обычаев народа, населяющего конкретную территорию, поэтому семейное право разных стран часто принципиально отличается, что, естественно, затрудняет юридическую регуляцию этой сферы.

Именно поэтому мировое сообщество в целях разрешения трансграничных семейнобрачных конфликтов идет по пути создания общих, то есть унифицированных норм права. Такие соглашения могут быть двух видов, а именно: 1) коллизионного; 2) материально-правового характера.

В первом случае на уровне международного соглашения (договора или конвенции) создаются правила, на основе которых спорящие стороны выбирают право конкретного государства (так называемое применимое право), которое и будет разрешать их противоречия. Проблема избрания такого правопорядка называется в международном частном праве коллизионной проблемой [9, с. 21-23]. В ситуации конфликта спорящие стороны вряд ли услышат аргументы друг друга, и каждый из них будет настаивать на применении наиболее благоприятного конкретно для него пра- 
ва. Чаще всего это бывает законодательство государства, к которому лицо принадлежит. Поэтому создание международного акта в этой области как наиболее авторитетного норматива - весьма удачное и рациональное решение коллизионной проблемы.

Второй вид унификации из вышеназванных предполагает создание общих материально-правовых норм, то есть таких, которые не отсылают к праву какой-то страны (таким образом избегают коллизионной стадии правоприменения), а непосредственно устанавливают права и обязанности участников правоотношения. Это наиболее трудный путь, поскольку добиться консенсуса между различными странами в области семейно-брачных отношений бывает очень сложно.

\section{Россия как участница международных соглашений, регулирующих семейно-брачные отношения с иностранным элементом}

В мире используются оба способа унификации в рассматриваемой сфере. В настоящее время создано более 20 международных соглашений в области брачно-семейных отношений $[1$, с. 545-546]. Тем не менее Российскую Федерацию сложно назвать активной участницей многосторонних международных договоров в области брачно-семейных отношений, так как к большему их количеству она не присоединилась [7, с. 7-9].

Наше отечество пошло по пути заключения двусторонних договоров о правовой помощи по гражданским, семейным и уголовным делам, в которых на основе коллизионного способа разрешается лишь часть семейно-брачных вопросов с иностранным элементом. Эти соглашения также не являются многочисленными. Они или достались России в наследство от СССР и заключены главным образом между странами, входившими в так называемый социалистический лагерь (Албания, Болгария, Венгрия, Вьетнам, КНДР, Польша, Словакия, Чехия и т. п.), или подписаны между государствами - бывшими республиками Советского Союза, такими как Кыргызстан, Латвия, Литва, Молдова, Эстония и др.
Фрагментарно проблематику трансграничных семейных отношений решают консульские конвенции, заключенные РФ с большинством стран, но об исчерпывающем регулировании рассматриваемой сферы и в этом случае говорить нельзя.

Несколько особняком в рамках подобных договоров находится Конвенция о правовой помощи и правовых отношениях по гражданским, семейным и уголовным делам (заключена в г. Минске 22 января 1993 г.). Это наиболее полный коллизионный источник, принятый между странами Содружества независимых государств, участницей которого является и Россия. Однако и этот норматив, и Конвенция о правовой помощи и правовых отношениях по гражданским, семейным и уголовным делам (заключена в г. Кишиневе 7 октября 2002 г.), которая должна заменить минское соглашение, не решают всей полноты возникающих проблем в области семьи и брака. Результатом такой «невнимательности» к рассматриваемым вопросам со стороны законодателя стали участившиеся случаи, когда российские граждане, попадая за границу, не получают должной правовой защиты. Например, необоснованно ограничиваются их имущественные права и права на общение и воспитание их детей и т. п. [5; $8 ; 16$; 17]. Поэтому все чаще в отечественном научном сообществе раздаются призывы о необходимости присоединения Российской Федерации к наиболее значимым многосторонним международным договорам в этой области $[6$, с. $123 ; 7 ; 11]$.

Оценивая указанные возможности, И.А. Трофимец и С.Ю. Ли выдвинули предложение о присоединении РФ к Гаагской конвенции от 14 марта 1978 г. «О заключении и признании действительности браков» (далее Конвенция) [10, с. 699-704]. Эти ученые отмечают, что российское семейное законодательство в целом соответствует положениям указанного договора, но трансформация его норм в правовую систему России станет юридической основой для защиты граждан РФ на международном уровне. Оно будет минимизировать возможность возникновения так называемых хромающих браков, то есть ситуаций, когда по законодательству одной страны брак считается действительным, а по праву 
другой - нет [15], тем более что положения Конвенции о форме и порядке, условиях заключения брака тождественны положениям отечественного законодательства. Детализируя сказанное, можно привести краткое сравнение подобных норм Конвенции и Раздела VII Семейного кодекса РФ (см. таблицу).

В рассматриваемом международном договоре есть и значимые с точки зрения права отличия от законодательства РФ, а именно: в ст. 4 Конвенции предусмотрено право государства потребовать от будущих супругов представления документов, подтверждающих содержание иностранного закона, подлежащего применению при заключении соответствующего брака. В п. 1 ст. 166 СК РФ уже предусмотрена обязанность суда, органов записи актов гражданского состояния и иных органов установить содержание норм иностранного семейного права.

Особенностью является и то, что содержание предусмотренной в ст. 5 Конвенции оговорки о публичном порядке менее категорично, чем положения ст. 167 СК РФ. В силу правил Конвенции иностранный правопорядок может не применяться, если нормы иностранного государства явно противоречат основам публичного правопорядка государства, где требуется признание брака, но при всем этом страна - участник Конвенции вправе признать уже заключенный брак действительным, даже в случае его противоречия своему публичному порядку. Таким образом, положения Конвенции более гибкие с точки зрения практического применения, так как предусматривают право
Договаривающегося государства отказать в применении иностранной нормы, а не обязанность, как об этом говорится в ст. 167 СК РФ.

\section{Гармонизация отечественного}

\section{семейного права в сфере международных} семейно-брачных отношений

Другим способом интеграции Российской Федерации в мировое пространство, в том числе в сфере семьи и брака, является последовательная гармонизация отечественных внутригосударственных норм с нормами других государств.

В российской действительности, в том числе и с признаками международности, существует большое количество так называемых гражданских браков, то есть не зарегистрированных в ЗАГСе фактически брачных отношений. В римском частном праве такие союзы называли конкубинатом, или сожительством. Поскольку в случае распада такого квазибрака нарушались имущественные и неимущественные права участников (или одного из них), в позднем римском частном праве такие отношения приравнивались к браку и потерпевшей стороне предоставлялась юридическая защита [2, с. 846-847]. К сожалению, отечественные законодатели пока не считают возможным пойти по пути древнеримских юристов... [3]

Действительно, можно не замечать наличие тех или иных проблем и под разным предлогом отказываться их решать. Подобный подход не способствует устранению зло-

\section{Нормы о форме и порядке, условиях заключения брака в Гаагской конвенции от 14 марта 1978 г. «О заключении и признании действительности браков» и Разделе VII Семейного кодекса РФ}

\begin{tabular}{|c|c|}
\hline \multicolumn{2}{|r|}{ Форма брака } \\
\hline $\begin{array}{l}\text { Ст. } 2 \text { Конвенции: «Формальные } \\
\text { требования к бракам регулируются } \\
\text { правом Государства заключения» }\end{array}$ & $\begin{array}{c}\text { П. } 1 \text { ст. } 156 \text { СК РФ: «Форма и порядок заключения } \\
\text { брака на территории РФ определяются } \\
\text { законодательством РФ» }\end{array}$ \\
\hline \multicolumn{2}{|c|}{ Условия заключения брака } \\
\hline $\begin{array}{c}\text { П. } 2 \text { ст. } 3 \text { Конвенции: «Брак } \\
\text { заключается: когда каждый из } \\
\text { будущих супругов удовлетворяет по } \\
\text { существу требованиям внутреннего } \\
\text { права, определенного коллизионными } \\
\text { нормами Государства заключения» }\end{array}$ & $\begin{array}{c}\text { П. } 2 \text { ст. } 156 \text { СК РФ: «Условия заключения брака на } \\
\text { территории РФ определяются для каждого из лиц, } \\
\text { вступающих в брак, законодательством государства, } \\
\text { гражданином которого лицо является в момент } \\
\text { заключения брака, с соблюдением требований ст. } 14 \\
\text { СК РФ в отношении обстоятельств, } \\
\text { препятствующих заключению брака» } \\
\end{array}$ \\
\hline
\end{tabular}


бодневных вопросов, а наоборот, приводит к их усилению и возникновению определенной социальной напряженности. По данным переписи 2010 г., из 34 млн браков в России более 3 млн (то есть каждый десятый) - основаны на сожительстве [19]. В силу неоднозначной социально-экономической ситуации в РФ эта цифра продолжает расти.

Рассматривая указанную проблематику, А.В. Слепакова предлагает фактическим супругам для решения имущественных вопросов использовать гражданско-правовые соглашения, основанные на положениях Гражданского кодекса РФ об общей долевой собственности [13, с. 413-416]. Можно воспользоваться и опытом Германии. В этой стране такого рода отношения регулируются Законом о зарегистрированных гражданских партнерствах от 16 февраля 2001 г. (вступил в силу 1 августа 2001 г.) [14, с. 27-28]. Однако и в этом случае придется регистрировать такого рода союзы, а чтобы сделать эту процедуру более привлекательной для живущих в таком «объединении», можно предложить их регистрацию не в ЗАГСе, а в нотариальных органах.

Сближение правопорядков разных стран, то есть их гармонизация, по нашему мнению, должна носить разумный характер и возможный компромисс - не затрагивать исторических, этических и религиозных основ нашего многонационального и многоконфессионального государства. В этом аспекте как раз и находится вопрос о признании и регистрации однополых браков. Суть проблемы заключается в том, что по нормам российского права официально зарегистрировать такой брак невозможно, поскольку браком как таковым в РФ в соответствии с п. 3 ст. 1 СК РФ признается союз между мужчиной и женщиной. Подобные союзы признаются браками в Великобритании, Дании, Нидерландах, Франции и других странах.

В целях легализации подобных отношений на территории РФ отечественные граждане нетрадиционной половой ориентации используют элементы обхода закона и несовершенство отечественного законодательства. Так, в п. 1 ст. 158 СК РФ установлено, что «браки между гражданами РФ и браки между гражданами РФ и иностранными гражданами или лицами без гражданства, заключен- ные за пределами территории РФ с соблюдением законодательства государства, на территории которого они заключены, признаются действительными в Российской Федерации, если отсутствуют предусмотренные статьей 14 СК РФ обстоятельства, препятствующие заключению брака». Проанализировав содержание этой нормы, указанные выше лица заключают однополый брак в стране, в которой он признается действительным, а затем обращаются в официальные органы РФ с заявлением о его признании [4; 18]. Формально, если действовать согласно с положениями указанной выше нормы, у сотрудников Многофункционального центра (МФЦ), где и решаются подобные вопросы, оснований отказать в признании и оформлении такого квазибрака нет. Тем не менее положительное решение такого вопроса, как это было сделано в одном из МФЦ г. Москвы в отношении граждан Е. Войцеховского и П. Стоцко, не согласуется ни с нормами общепринятой этики, ни с отечественным правосознанием и по сути противоречит публичному порядку. Однако убедительных правовых основ для отказа в признании такого рода союза у правоприменителей в РФ не существует. Более того, документы о регистрации подобного брака могут быть надлежащим образом оформлены (легализованы), например, на основе Конвенции, отменяющей требование легализации иностранных официальных документов (заключена в г. Гааге 5 октября 1961 г., вступила в силу для России 31 мая 1992 г.).

Этот брак все же не был зарегистрирован в России, так как органы МВД РФ волевым порядком аннулировали паспорта указанных граждан [12]. Однако такой путь ведет непосредственно к рассмотрению подобных споров в Европейском суде по правам человека, в котором следует гарантированно ожидать проигрыша РФ, и выплате указанным лицам определенной компенсации. А как еще могут поступить гендерно-толерантные европейские судьи?..

Не спасет в рассматриваемом случае, по нашему мнению, и обращение к нормам, содержащим оговорку о публичном порядке (см. ст. 1193 ГК РФ и ст. 167 СК РФ). Использовать указанные статьи, исходя из их содержания, возможно только в том случае, 
если применяются нормы иностранного права. При регистрации же однополого брака на территории другого государства, как это было рассмотрено в вышеуказанном примере, не возникает вопроса о применении таких норм, а происходит несколько другой процесс, а именно признание действительности акта (действия) иностранного государства на территории другой страны. В силу принципа «locus regit actum» ${ }^{1}$ и равенства суверенитетов государств такой акт без наличия специальных законодательных решений признать недействительным будет юридически крайне затруднительно.

\section{Выводы}

Подводя итог изложенному выше и оценивая отдельные способы совершенствования законодательства РФ в области брачно-семейных отношений с иностранным элементом, нужно отметить, что Российской Федерации, на наш взгляд, не следует изолировать себя от участия в международной унификации и гармонизации в рассматриваемой сфере. Отказ от этих процессов идет в ущерб интересам граждан России, но эти процедуры не могут носить бездумный характер и не должны нарушать принципы нравственности и морали, сложившиеся в процессе многовекового развития нашего отечества, особенно в части признания однополых браков, а для этого, как нам представляется, необходимо решить три тактические задачи. Во-первых, следует дополнить содержание ст. 158 СК РФ пунктом 3 следующего содержания: «Однополые, равно как и полигамные браки, в Российской Федерации не признаются в силу противоречия их публичному порядку Российской Федерации». Такая мера усилит позицию не только отечественных судов, но и иных правоприменительных органов в сфере трансграничных отношений. Во-вторых, законодатель либо в отдельной норме, либо в рамках ст. 1193 ГК РФ и ст. 167 СК РФ должен указать, что их действие возможно не только в случаях применения норм иностранного права, но и в ситуациях признания актов другого государства на территории РФ. В-третьих, Верховный суд РФ должен в одном из своих актов по толкованию законодательства РФ подробно разъяснить, что понимается в российском праве в качестве публичного порядка и когда и как применимы нормы ст. 1193 ГК РФ и ст. 167 СК РФ.

\section{ПРИМЕЧАНИЕ}

${ }^{1}$ В силу этого принципа содержание и форма юридического акта определяются правом государства места его совершения, а не места признания.

\section{СПИСОК ЛИТЕРАТУРЫ}

1. Ануфриева, Л. П. Международное частное право. В 3 т. Т. 2 / Л. П. Ануфриева. - М. : БЕК, 2002. $-768 \mathrm{c}$.

2. Барон, Ю. Система Римского гражданского права : в 6 кн. / Ю. Барон. - СПб. : Юридический центр Пресс, 2005. - 1102 с.

3. В Госдуме раскритиковали идею приравнять сожительство к браку// Ria.ru. - Электрон. текстовые дан. - Режим доступа: https://ria.ru/20180122/ 1513061913. html. - Загл. с экрана.

4. Двое россиян заявили о первом признанном в России однополом браке// Rbc.ru. - Электрон. текстовые дан. - Режим доступа: https://www.rbc.ru/ society/ 25/01/2018/5a6a28509a79473e917b3263. - Загл. с экрана.

5. «Жертва сирийского кризиса»: власти Франции намерены выслать россиянку, разлучив с новорожденным ребенком // Russian.rt.com. - Электрон. текстовые дан. - Режим доступа: https:// russian.rt.com/world/article/507121-rossiyankafranciya-rebenok. - Загл. с экрана.

6. Звеков, В. П. Коллизии законов в международном частном праве / В. П. Звеков. - М. : Волтерс Клувер, 2007. - 416 с.

7. Иловайский, И. Б. Правовое регулирование брачно-семейных отношений с иностранным элементом : учеб. пособие / И. Б. Иловайский. - Волгоград : Изд-во Волгогр. фил. ФГБОУ ВПО РАНХиГС, 2016. $-73 \mathrm{c}$.

8. Как и почему отнимают российских детей за границей. Пять вопиющих случаев изъятия детей у россиян в Европе // Iz.ru. - Электрон. текстовые дан. - Режим доступа: https://iz.ru/news/633664. Загл. с экрана.

9. Канашевский, В. А. Международное частное право : учебник // В. А. Канашевский. - М. : Международные отношения, 2016. - 1008 c.

10. Конвенция о заключении и признании действительности браков (Заключена в г. Гааге 14.03.1978). - Доступ из справ.-правовой системы «КонсультантПлюс». 
11. Марышева, Н. И. Семейные отношения с участием иностранцев: правовое регулирование в России / Н. И. Марышева. - М. : Волтерс Клувер, 2007. $-328 \mathrm{c}$.

12. Паспорта зарегистрировавших брак в Москве геев аннулированы // Vz.ru. - Электрон. текстовые дан. - Режим доступа: https://vz.ru/news/2018/ 1/26/905443.html. - Загл. с экрана.

13. Слепакова, А. В. Правоотношения собственности супругов / А. В. Слепакова. - М. : Эксмо, 2005. - 444 c.

14. Тагаева, С. Н. Признание брака недействительным в Республике Таджикистан и отмена брака в Германии как меры семейно-правовой ответственности / С. Н. Тагаева // Семейное и жилищное право. -2012. - № 6. - С. 27-28.

15. Трофимец, И. А. К вопросу о международноправовом регулировании брачных отношений с участием иностранцев / И. А. Трофимец, С. Ю. Ли // Семейное и жилищное право. - 2010. - № 6. - С. 21-26.

16. Финская прокуратура обвинила россиянку Салонен в похищении ребенка // Ria.ru. - Электрон. текстовые дан. - Режим доступа: https://ria.ru/ 20090915/ 185147037.html. - Загл. с экрана.

17. Финский правозащитник сообщил об изъятии пятилетней дочери у россиянки // News.rambler. Электрон. текстовые дан. - Режим доступа: https:// news.rambler.ru/world/41315144/?utm_content= rnews\&utm_medium=read_more\&utm_source =copylink. - Загл. с экрана.

18. Член СПЧ прокомментировала первый зарегистрированный однополый брак в России // Vz.ru. Электрон. текстовые дан. - Режим доступа: https:// vZ.ru/news/2018/1/26/905362.html. - Загл. с экрана.

19. Шуваева, В. От гостевого до конкубината. Социолог о новых видах брака и частых разводах / В. Шуваева // Perm.aif.ru. - Электрон. текстовые дан. Режим доступа: http://www.perm.aif.ru/society/people/ semya_byla_i_budet_na_chyom_derzhatsya_braki i_pochemu_proishodyat_razvody. - Загл. с экрана.

\section{REFERENCES}

1. Anufrieva L.P. Mezhdunarodnoe chastnoe pravo. $V 3$ t. T 2 [Private International Law. In 3 vols. Vol. 2]. Moscow, BEK Publ., 2002. 768 p.

2. Baron Yu. Sistema Rimskogo grazhdanskogo prava: $v 6 \mathrm{kn}$. [Roman Civil Law System. In 6 books]. Saint Petersburg, Yuridicheskiy tsentr Press Publ., 2005. 1102 p.

3. V Gosdume raskritikovali ideyu priravnyat sozhitelstvo k braku [The State Duma Criticized the Idea of Equating Cohabitation to Marriage]. Ria.ru. URL: https://ria.ru/20180122/1513061913.html.

4. Dvoe rossiyan zayavili o pervom priznannom v Rossii odnopolom brake [Two Russians Announced the First Recognized in Russia Same Sex Marriage]. Rbc.ru. URL: https://www.rbc.ru/society/ 25/01/2018/ 5a6a28509a79473e917b3263.

5. «Zhertva siriyskogo krizisa»: vlasti Frantsii namereny vyslat rossiyanku, razluchiv $\mathrm{s}$ novorozhdennym rebyenkom ["Victim of the Syrian Crisis": French Authorities Intend to Expel a Russian Woman, Separated from a Newborn Child]. Russian.rt.com. URL: https://russian.rt.com/world/ article/507121-rossiyanka-franciya-rebenok.

6. Zvekov V.P. Kollizii zakonov v mezhdunarodnom chastnom prave [Conflicts of Laws in Private International Law]. Moscow, Volters Kluver Publ., 2007. 416 p.

7. Ilovaisky I.B. Pravovoe regulirovanie brachno-semeynykh otnosheniy s inostrannym elementom: uchebnoe posobie [Legal Regulation of Marriage and Family Relations with a Foreign Element: Textbook]. Volgograd, Izd-vo Volgogradskogo filiala FGBOUVPORANKhiGS, 2016.73 p.

8. Kak i pochemu otnimayut rossiyskikh detey za granitsey. Pyat vopiyushchikh sluchaev izyatiya detey $\mathrm{u}$ rossiyan v Evrope [How and Why Russian Children are Taken Away Abroad. Five Egregious Cases of Seizure of Children from Russians in Europe]. Iz.ru. URL: https://iz.ru/news/633664.

9. Kanashevsky V.A. Mezhdunarodnoe chastnoe pravo: uchebnik [Private International law: Textbook]. Moscow, Mezhdunarodnye otnosheniya Publ., 2016. 1008 p.

10. Konventsiya o zaklyuchenii $i$ priznanii deystvitelnosti brakov (Zakliuchena $v$ g. Gaage 14.03.1978) [Convention on Celebration and Recognition of the Validity of Marriages (Hague, 14.III.1978)]. Access from Reference Legal System "KonsultantPlyus".

11. Marysheva N.I. Semeynye otnosheniya s uchastiem inostrantsev: pravovoe regulirovanie $v$ Rossii [Family Relations Involving Foreigners: Legal Regulation in Russia]. Moscow, Volters Kluver Publ., 2007. 328 p.

12. Pasporta zaregistrirovavshikh brak v Moskve geev annulirovany [Passports Registered Marriage in Moscow Gays Canceled]. Vz.ru. URL: https://vz.ru/ news/2018/1/26/905443.html.

13. Slepakova A.V. Pravootnosheniya sobstvennosti suprugov [Legal Relations of Property of Spouses]. Moscow, Eksmo Publ., 2005. 444 p.

14. Tagaeva S.N. Priznanie braka nedeystvitelnym v Respublike Tadzhikistan i otmena braka v Germanii kak mery semeyno-pravovoy otvetstvennosti [Annulment of Marriage in Tajikistan and Annulment of Marriage in Germany as Measures of Family Legal Responsibility]. Semeynoe i zhilishchnoe pravo, 2012, no. 6, pp. 27-28.

15. Trofimets I.A., Li S.Yu. K voprosu o mezhdunarodno-pravovom regulirovanii brachnykh 
otnosheniy s uchastiem inostrantsev [On the Issue of International Legal Regulation of Marriage Relations Involving Foreigners]. Semeynoe $i$ zhilishchnoe pravo, 2010, no. 6, pp. 21-26.

16. Finskaya prokuratura obvinila rossiyanku Salonen v pokhishchenii rebyenka [Finnish Prosecutors Have Accused the Russian Salonen Child Abduction]. Ria.ru. URL: https://ria.ru/20090915/ 185147037.html.

17. Finskiy pravozashchitnik soobshchil ob izyatii pyatiletney docheri u rossiyanki [The Finnish Human Rights Activist Reported about Withdrawal of the Five-Year-Old Daughter from the Russian]. News.rambler.ru. URL: https://world/41315144/ ?utm_content $=$ rnews\&utm_medium=read_more \&utm_source=copylink.

18. Chlen SPCh prokommentirovala pervyy zaregistrirovannyy odnopolyy brak v Rossii [HRC Member Commented on the First Registered Same Sex Marriage in Russia]. Vz.ru. URL: https://vz.ru/news/ 2018/1/26/905362.html.

19. Shuvaeva V. Ot gostevogo do konkubinata. Sotsiolog o novykh vidakh braka i chastykh razvodakh [From the Guest to Concubinate. Sociologist on New Types of Marriage and Frequent Divorces]. Perm.aif.ru. URL: http://www.perm.aif.ru/society/ people/semya_byla_i_budet_na_chyom_ derzhatsya_braki_i_pochemu_proishodyat_razvody.

\section{Information about the Authors}

Igor B. Ilovaisky, Candidate of Sciences (Jurisprudence), Associate Professor, Department of Civil and International Private Law (Base Department of The Southern Scientific Centre of the Russian Academy of Sciences), Volgograd State University, Prosp. Universitetsky, 100, 400062 Volgograd, Russian Federation, domino@rambler.ru, https://orcid.org/0000-0002-4210-9413

Valeria Yu. Dolgova, Legal Adviser, Limited Liability Company “CrimExpertYug”, Selenginskaya St., 16, 400050 Volgograd, RussianFederation, valeriad2012@mail.ru, https://orcid.org/0000-0001-7473-2886

\section{Информация об авторах}

Игорь Борисович Иловайский, кандидат юридических наук, доцент кафедры гражданского и международного частного права (базовая кафедра ЮНЦ РАН), Волгоградский государственный университет, просп. Университетский, 100, 400062 г. Волгоград, Российская Федерация, domino@rambler.ru, https://orcid.org/0000-0002-4210-9413

Валерия Юрьевна Долгова, юрисконсульт, ООО «КримЭкспертЮг», ул. Селенгинская, 16, 400050 г. Волгоград, Российская Федерация, valeriad2012@mail.ru, https://orcid.org/0000-0001-7473-2886 